\title{
Meso-scale aurora within the expansion phase bulge
}

\author{
N. Partamies ${ }^{1}$, K. Kauristie ${ }^{2}$, E. Donovan ${ }^{1}$, E. Spanswick ${ }^{1}$, and K. Liou ${ }^{3}$ \\ ${ }^{1}$ Department of Physics and Astronomy, University of Calgary, Calgary, Alberta, Canada \\ ${ }^{2}$ Finnish Meteorological Institute, Space Research Unit, Helsinki, Finland \\ ${ }^{3}$ The Johns Hopkins University Applied Physics Laboratory, Laurel, Maryland, USA
}

Received: 18 August 2005 - Revised: 13 June 2006 - Accepted: 28 July 2006 - Published: 13 September 2006

\begin{abstract}
We present ground-based optical, riometer and magnetometer recordings together with Polar UVI and GOES magnetic field observations of a substorm that occurred over Canada on 24 November 1997. This event involved a clear optical onset followed by poleward motion of the aurora as a signature of an expanding auroral bulge. During the expansion phase, there were three distinct types of meso-scale (10-1000 km) auroral structures embedded in the bulge: at first a series of equatorward moving auroral arcs, followed by a well-defined spiral pair, and finally northsouth directed aurora (a streamer). The spirals occurred several minutes after the onset, and indicate a shear in the fieldaligned current. The north-south aligned aurora that formed about $10 \mathrm{~min}$ after the onset suggest bursty bulk flow type flows taking place in the central plasma sheet. Polar UVI observations of the polar cap location indicate that the southward drifting arcs were associated with magnetospheric activity within closed field lines, while the auroral streamer was launched by the bulge reaching the polar cap boundary, i.e. the mid-tail reconnection starting on the open field lines. The riometer data imply high energy electron precipitation in the vicinity of the the poleward moving edge of the auroral bulge, starting at the onset and continuing until the formation of the north-south structure. In this paper, we examine this evolving auroral morphology within the context of substorm theories.
\end{abstract}

Keywords. Ionosphere (Auroral ionosphere; Ionospheremagnetosphere interactions) - Magnetospheric physics (Storms and substorms)

Correspondence to: N. Partamies

(noora@ phys.ucalgary.ca)

\section{Introduction}

\subsection{The substorm concept and models}

The reconnection of the interplanetary and the terrestrial magnetic fields on the dayside magnetopause provides the energy that powers the substorm cycle. Newly opened flux tubes drift downstream towards the magnetotail adding to the magnetic flux of the tail lobes. During the growth phase, energy is added faster than it can be processed by the largescale convection (McPherron, 1972). As a result, the magnetotail stretches, the cross-tail current increases and the plasma sheet thins. At the expansion phase onset, what is in most cases the most equatorward auroral arc intensifies, becomes dynamic and propagates poleward. A bulge forms in this breakup region and expands poleward as well as eastward and westward along the oval. The Westward Travelling Surge (WTS) is usually observed as an auroral display at the expanding western edge of the bulge.

The main ionospheric signatures of a substorm have been described by e.g. Akasofu (1964) and Elphinstone et al. (1996). Ground magnetometers often detect Pi2 pulsations (Yumoto et al., 1989). Particle injections (Reeves et al., 1990) and magnetic field dipolarisation (Liou et al., 2002) are observed at geosynchronous orbit. The dipolarisation reflects the decrease in the cross-tail current that goes hand-in-hand with the current diversion through the ionosphere and the "negative bay" in the magnetic X-component on the ground. In classic substorms there is a decrease in the area of the polar cap that indicates lobe flux reconnection on the nightside. The merging of the tail field can lead to the formation and subsequent ejection of a plasmoid downtail. Events that do not involve lobe-flux reconnection are usually referred to as pseudo-breakups (e.g. Pulkkinen, 1996).

The process starting the substorm expansion in the tail defines the main difference between the two most widely discussed substorm models. According to the Near-Earth

Published by Copernicus GmbH on behalf of the European Geosciences Union. 
Neutral Line (NENL) model (Baker et al., 1996; Shiokawa et al., 1998), the expansion phase starts with reconnection in the mid-tail at 20-30 $R_{E}$ from the Earth. Plasma flows accelerated earthward from the $\mathrm{X}$-line slow down in the stronger and more dipolar magnetic field closer to the Earth $\left(6-10 R_{E}\right)$. This results in a pile-up of the magnetic flux. The increase in flux corresponds to the dipolarisation and the diversion of the cross-tail current as Field-Aligned Currents (FAC) into the ionosphere to form the Substorm Current Wedge (SCW). Compressional pulses initiated from the flow braking point (the pile-up region) propagate earthward causing $\mathrm{Pi} 2$ pulsations and particle injection at the geosynchronous orbit (Shiokawa et al., 1998).

According to the Current Disruption (CD) model (Lui, 1996, 2001), instabilities generate fluctuations in the magnetic and electric fields increasing the resistivity in the crosstail current region. This leads to the diversion of the current to the ionosphere and the corresponding dipolarisation. Candidates for the near-Earth plasma sheet instabilities are, for instance, the cross-field current (Lui et al., 1991) and the ballooning instability (Roux et al., 1991). The instability in the earthward end of the plasma sheet propagates tailward as a rarefaction wave thinning the plasma sheet and resulting in conditions favourable for reconnection.

In both models, the current wedge is recognised as the self-consistent corollary to the current disruption in the nearEarth Central Plasma Sheet (CPS). In the CD model scenario, the poleward auroral expansion during the expansion phase is an ionospheric signature of the tailward propagating rarefaction wave and follows the onset. In the NENL model, the poleward expansion is an ongoing signature of the mid-tail reconnection which launches fast Earthward flows (Bursty Bulk Flows or BBF's, Angelopoulos et al., 1992), which in turn cause the flux pile-up in the earthward end of the plasma sheet, the disruption of the cross-tail current and the dipolarisation.

\subsection{Meso-scale auroral structures within the bulge}

The transition region between the dipolar and the tail-like field lines (at about 6-12 $R_{E}$ ) is potentially unstable for ballooning instability (Hameiri et al., 1991). Earthward directed magnetic and pressure gradients can cause a surface wave type perturbation in this transition region. The perturbation propagates westward along the drifting ions. Positive (negative) charge accumulates at the leading (trailing) edge of the propagating wave structure due to the different drift speeds of the particles on tail-like and dipolar field lines. The excess of electric charge can then be neutralised by the FACs diverting into the ionosphere. Coupled to the Kelvin-Helmholtz instability, the ballooning instability has been used for explaining the formation of large-scale auroral vortices close to the poleward boundary of the bright proton aurora (Voronkov et al., 2000) as well as the triggering of a substorm expansion phase or a substorm intensification (e.g. Erickson et al., 2000;
Liu, 1997). Spiral formation has also been modelled by a localised shear in FACs (Hallinan, 1976) which can be found at essentially any time and embedded in essentially any current sheet in the auroral ionosphere. This process can form a spiral if there is an increase in a FAC filament, and a threshold for the current density $\left(\sim 2.5 \mu \mathrm{A} / \mathrm{m}^{2}\right)$ is fulfilled (Hallinan, 1976).

Poleward Boundary Intensifications (PBIs, Lyons et al., 1999) are auroral brightenings near the polar cap boundary and have traditionally been identified in keograms. Twodimensional image data show that PBIs can occur as arcs that are east-west aligned or tilted with respect to the polar cap boundary (e.g. Zesta et al., 2002). They may also appear as latitudinally more localised structures that often evolve into North-South (N-S) aligned aurora. PBIs can remain at the boundary or propagate equatorward. In several event studies, the N-S aurora that sometimes evolve from PBIs have been related on a one-to-one basis to transient earthward flows in the CPS (e.g. Zesta et al., 2000). On the other hand, equatorward propagating arcs may be related to azimuthally broad phase fronts of earthward propagating disturbances in the plasma sheet (Zesta et al., 2002).

As a theoretical example, the bubble model of Pontius and Wolf (1990) explained the fast flows in the plasma sheet as strongly earthward elongated, transient low-density channels. The drift velocities inside and outside the bubble (the flow channel) are different causing a charge accumulation and enhanced electric field that is consistent with the fast flow. The charge separation is neutralised by the formation of a FAC loop to the ionosphere and N-S aurora (a streamer). Phenomenologically, the N-S structures often occur within the auroral bulge. They form at the poleward boundary of the auroral oval, intrude rapidly equatorward (Amm and Kauristie, 2002, and references therein) and cause a local brightening at the equatorward part of the oval when reaching it (Sergeev et al., 2001). They appear roughly $10 \mathrm{~min}$ after the breakup and recur quasi-periodically, so that fluctuations can be seen in the ground magnetic field recordings. In the NENL model, streamers are ionospheric manifestations of BBFs between the reconnection site and the plasma pileup region (Henderson et al., 1998). According to the CD model, the earthward flows in the CPS are related to convection surges (Lui, 1996) or the tailward propagation of the rarefaction wave.

The auroral ionosphere is often referred to as a television screen showing the projection along magnetic field lines of magnetospheric processes during substorms. In this context, the ground- and space-based optical observations are used to monitor the location of the important magnetospheric regions such as the near-Earth transition region from the dipolar to the stretched magnetic field configuration, or the polar cap boundary (Blanchard et al., 1995; Brittnacher et al., 1999; Donovan et al., 2003). In this paper, we use optical and geostationary data to study the appearance of meso-scale structures (arcs, spirals and streamers) within a poleward 


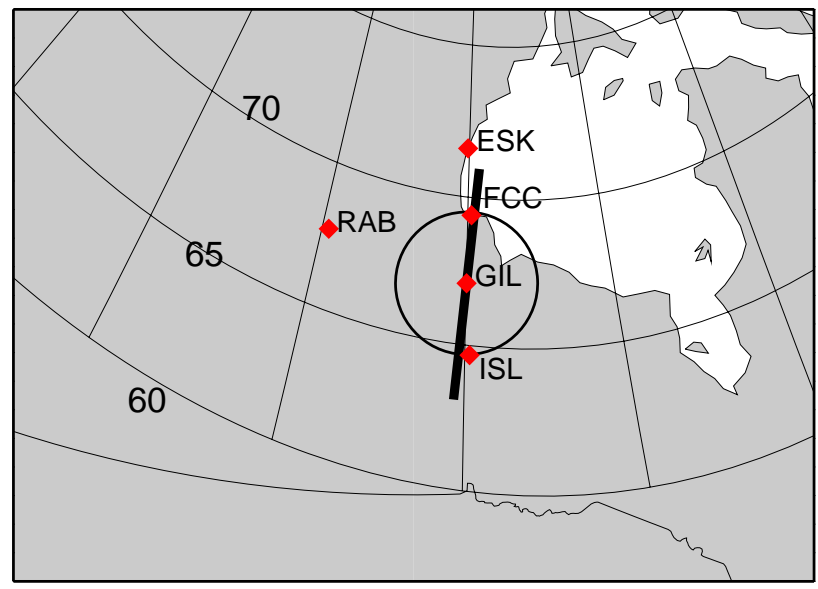

Fig. 1. The locations of the Canadian fluxgate magnetometers (red diamonds). The FoVs of the Gillam ASI and MSP are indicated by the black circle and thick black line, respectively. The contours show the PACE invariant geomagnetic latitude and longitude (Baker and Wing, 1989). The longitude contours are separated by one hour in MLT.

expanding bulge. We discuss the optical signatures of earthward flows associated with the nightside reconnection of both closed and open field lines and compare our findings with the CD and NENL substorm scenarios. We will first describe the instrumentation in Sect. 2, then introduce the observations of this substorm event in Sect. 3. Discussion of the observations within the context of the above mentioned substorm models is provided in Sect. 4, and conclusions in Sect. 5 .

\section{Instrumentation}

This section contains an overview of the ground-based and satellite instrumentation that provided the data used in this study. The event we present in this paper occurred over central Canada on 24 November 1997.

The locations of the Canadian Auroral Network for the OPEN Program Unified Study (CANOPUS) (Rostoker et al., 1995) stations used in this study are shown in Fig. 1. The Gillam (GIL) All-Sky Imager (ASI) Field-of-View (FoV) covers a circular area with a diameter of about $600 \mathrm{~km}$ at the altitude of $110 \mathrm{~km}$. The size of the captured image is $200 \times 200$ pixels giving the average spatial resolution of about $3 \mathrm{~km}$ (or $\left.0.75^{\circ}\right)$. Images of both the auroral green $(557.7 \mathrm{~nm})$ and red $(630.0 \mathrm{~nm})$ emissions are collected at a cadence of one per minute using exposure times of $1.6 \mathrm{~s}$.

Single-beam riometers (Rostoker et al., 1995) with a FoV of $60^{\circ}$ at all of the CANOPUS sites record data at the temporal resolution of $5 \mathrm{~s}$. While there are caveats, riometer absorption in general indicates precipitating particles with energies of about $10-100 \mathrm{keV}$. In this study, we use the data from Island Lake (ISL), Gillam (GIL), Fort Churchill (FCC),
Table 1. Geographic latitude and longitude and PACE invariant geomagnetic latitude (Baker and Wing, 1989) of the CANOPUS stations that produced data used in this study.

\begin{tabular}{lcccc}
\hline Station & Abbreviation & Geographic Lat,Lon & PACE Lat & CGM Lat \\
\hline Island Lake & ISL & $53.86^{\circ} \mathrm{N}, 265.34^{\circ} \mathrm{E}$ & $64.93^{\circ}$ & $64.35^{\circ}$ \\
Gillam & GIL & $56.38^{\circ} \mathrm{N}, 265.36^{\circ} \mathrm{E}$ & $67.37^{\circ}$ & $66.79^{\circ}$ \\
Fort Churchill & FCC & $58.76^{\circ} \mathrm{N}, 265.92^{\circ} \mathrm{E}$ & $69.71^{\circ}$ & $69.10^{\circ}$ \\
Rabbit Lake & RAB & $58.22^{\circ} \mathrm{N}, 256.32^{\circ} \mathrm{E}$ & $67.76^{\circ}$ & $67.45^{\circ}$ \\
Fort Smith & FSM & $60.03^{\circ} \mathrm{N}, 248.07^{\circ} \mathrm{E}$ & $67.91^{\circ}$ & $67.75^{\circ}$ \\
\hline
\end{tabular}

Rabbit Lake (RAB), and Fort Smith (FSM) (for station coordinates, see Table 1).

In addition, we use data from the CANOPUS Meridian Scanning Photometer (MSP) at GIL, which monitors the emissions at $557.7 \mathrm{~nm}, 630.0 \mathrm{~nm}, 486.1 \mathrm{~nm}$ (proton) and $470.9 \mathrm{~nm}$ (blue) along north-south scans. Assuming an emission altitude of $110 \mathrm{~km}$, its FoV extends roughly from $60^{\circ} \mathrm{CGMlat}$ to $73^{\circ} \mathrm{CGMlat}\left(49^{\circ}-63^{\circ} \mathrm{Glat}\right)$. The average longitudinal resolution is $0.2^{\circ}(\sim 20 \mathrm{~km})$, and the timeresolution is $30 \mathrm{~s}$.

Global auroral images from the Ultraviolet Imager (UVI) experiment (Torr et al., 1995) on board the Polar satellite capture activity of the auroral oval. We use images from Lyman-Brige-Hopfield long (LBHL, at 160-180 nm) filter which are taken about 3 min apart. During the event studied here, the Polar UVI FoV covers approximately the whole northern nightside oval. The spatial resolution of the UV images is about $40 \mathrm{~km}$ in the direction across the oval and about $400 \mathrm{~km}$ along the oval.

The National Oceanic and Atmospheric Administration (NOAA) GOES 8 and 9 geostationary satellites had their footpoints on either side of the activity region. We use magnetic field data from the GOES onboard fluxgate magnetometers (key parameters from CDAWeb) to identify the dipolarisations at the geosynchronous orbit. We also use key parameter magnetic field data from the Interball Tail satellite in the tail lobe $\left(\mathrm{X}_{\mathrm{GSM}} \sim-24 R_{E}, \mathrm{Y}_{\mathrm{GSM}} \sim 1 R_{E}, \mathrm{Z}_{\mathrm{GSM}} \sim 7.5 R_{E}\right)$ for following the strength of the lobe magnetic field, and key parameter magnetic and solar wind data from the Wind satellite $\left(\mathrm{X}_{\mathrm{GSM}} \sim 185 R_{E}, \mathrm{Y}_{\mathrm{GSM}} \sim 15 R_{E}, \mathrm{Z}_{\mathrm{GSM}} \sim 30 R_{E}\right.$ ) to estimate the energy transfer from the solar wind to the magnetosphere.

\section{Observations of the substorm}

\subsection{Overview of the activity}

In this section we describe observations of a substorm which occurred over the CANOPUS network between 01:0004:00 UT ( 18:30-21:30 Magnetic Local Time, MLT) on 24 November 1997. IMF $B_{Z}$ had been negative since $\sim$ 21:00 UT on the previous day. During this prolonged 

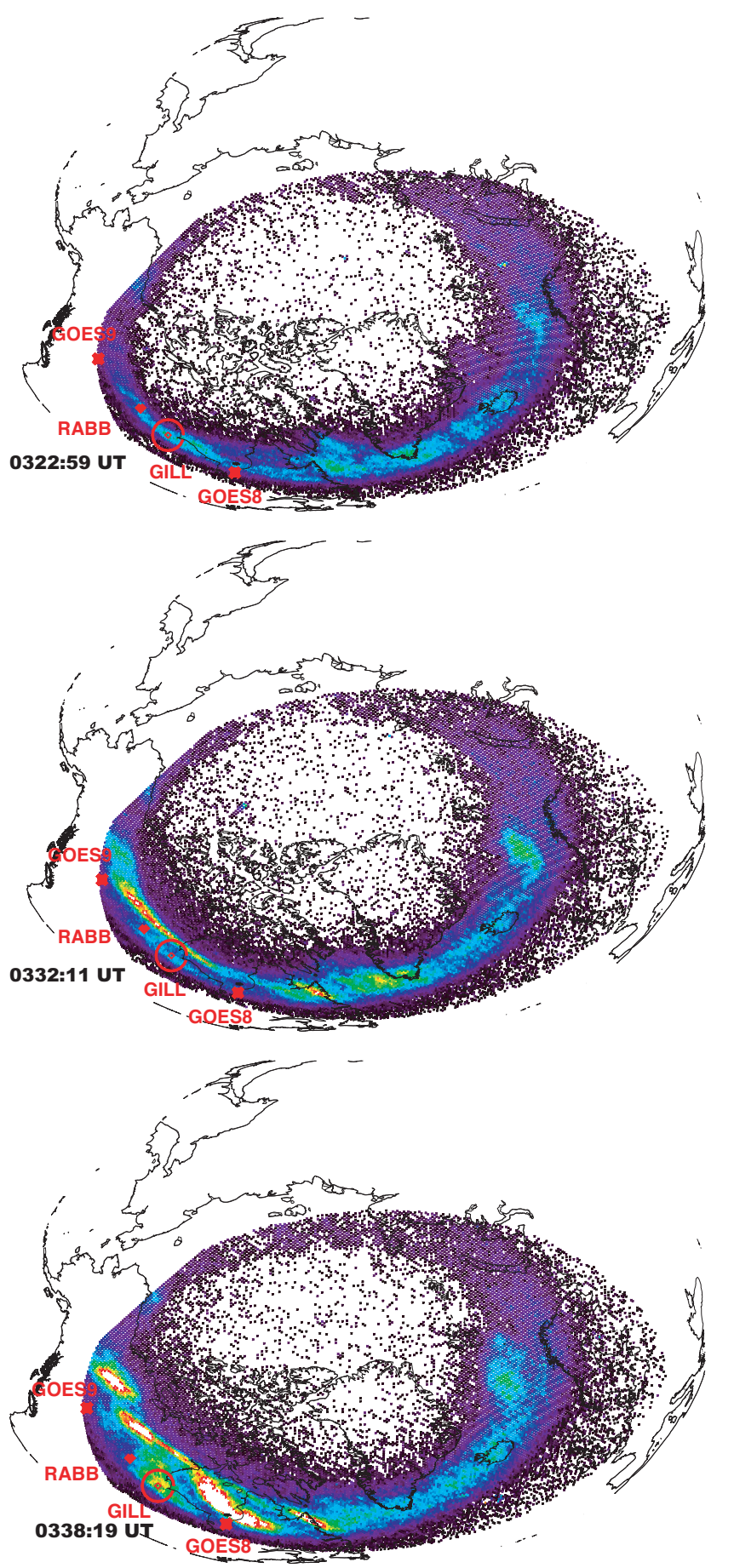

Fig. 2. Three Polar UVI (LBHL) images taken at 03:22:59 UT, 03:32:11 UT and 03:38:19 UT show the auroral bulge with the most intense precipitation at the poleward edge and only faint arcs inside. Red asterisks mark the footpoint of the GOES 8 and 9 satellites, and the ground magnetometer and riometer station at Rabbit Lake (RABB). The red circle shows an estimate of the ASI FoV at Gillam (GILL). Magnetic local midnight is down in the figure.

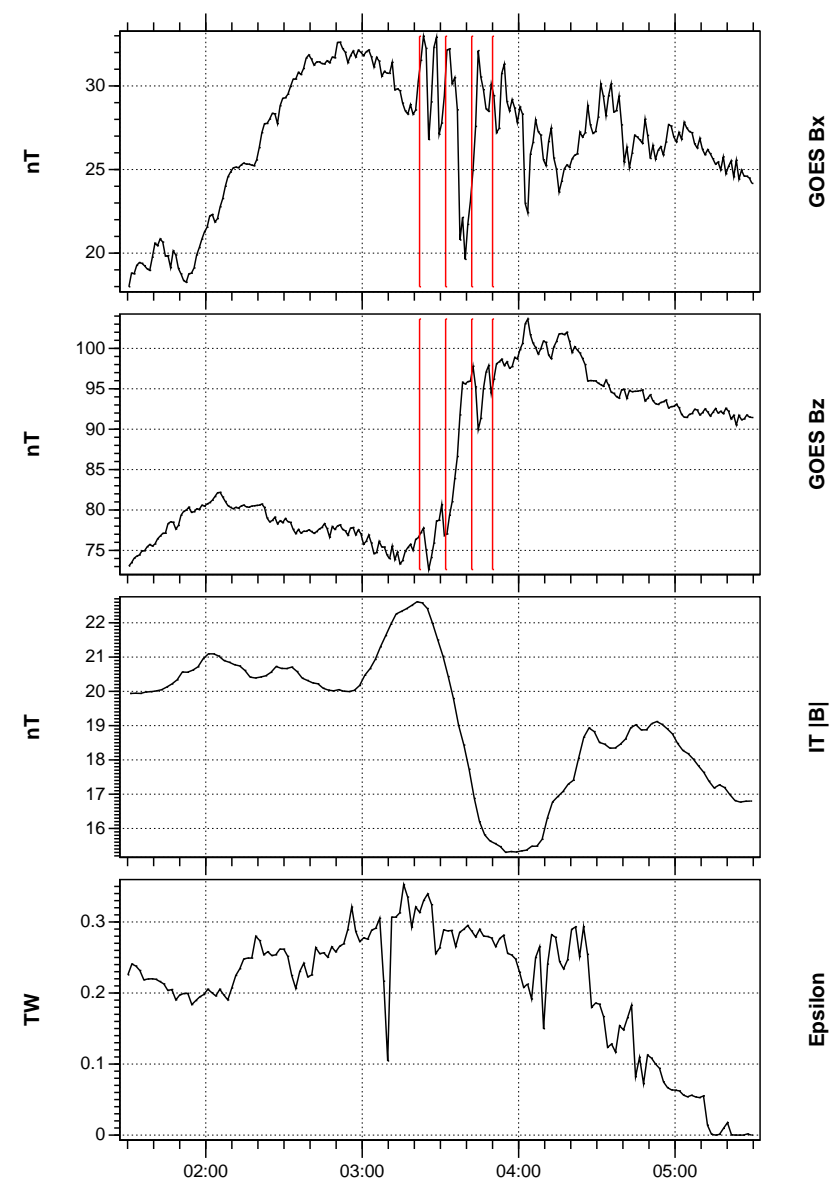

Fig. 3. $B_{X}$ and $B_{Z}$ from GOES-8 satellite (first and second panel) and total $\mathrm{B}$ from Interball Tail satellite $\left(\mathrm{X}_{\mathrm{GSM}}=-24 R_{E}\right.$, $\mathrm{Y}_{\mathrm{GSM}}=2 R_{E}, \mathrm{Z}_{\mathrm{GSM}}=7 R_{E}$, bottom panel). The vertical lines show the poleward motions experienced by the equatorward boundary of the proton emission band at 03:22, 03:32, 03:42 and 03:50 UT. The bottom panel shows the evolution of the Akasofu's epsilon parameter as propagated to the magnetopause.

period of southward IMF there were numerous small activations in the auroral ionosphere as seen in the Polar UVI images. The beginning of the substorm growth phase, identified by southward drifting arcs and a slow decrease in the $\mathrm{X}$-component of the ground magnetic field, was observed at Gillam at around 01:00 UT. There were at least two smaller activations that we interpret as pseudo-breakups $(\sim 02: 24$ and $\sim 03: 10$ UT) recorded at Gillam during the growth phase. The Auroral Electrojet (AE) index varied in range 200$400 \mathrm{nT}$ at 02:00-03:00 UT. It decreased to the minimum of $150 \mathrm{nT}$ at around 03:30 UT, rapidly increased to $550 \mathrm{nT}$ within the next minute and then decayed within the following $1.5 \mathrm{~h}$.

As seen from the Polar UVI images (Fig. 2), the oval was latitudinally wide in the midnight sector and narrow in the evening sector prior to the substorm expansion phase. The oval broadened in the evening and midnight sectors during 


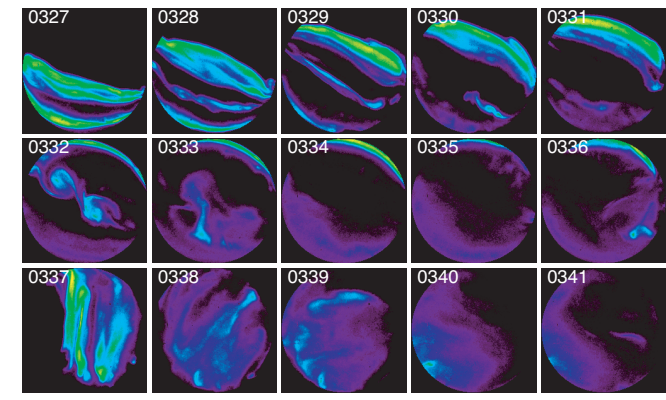

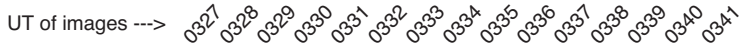

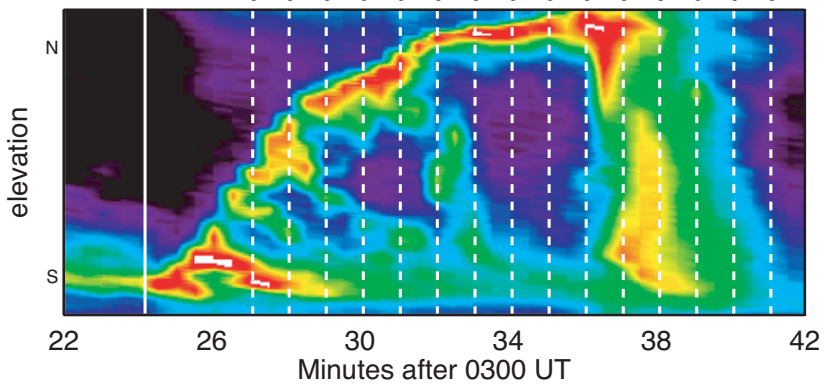

Fig. 4. A series of GIL ASI images during the substorm with one minute imaging interval (upper panel) and the MSP recordings of the green $(557.7 \mathrm{~nm})$ emission line (lower panel) as a function of the zenith angle and UT. Image times are marked on the MSP data by the white dashed lines, and the solid vertical line shows the time of the initial brightening at 03:24 UT.

the expansion phase activity. Tilted streamers grew and faded in different parts of the oval during the substorm sequence. The intense precipitation of the breakup arc stayed at the edge of the poleward expanding bulge (03:26-03:35 UT). Only faint arcs and unstructured precipitation were observed inside the bulge until the more intense N-S aurora crossed the oval over Gillam at 03:37 UT.

Figure 3 shows magnetic field data from the geostationary GOES 8 satellite (two upper panels for $\mathrm{X}$ and $\mathrm{Z}$ components) and from the Interball Tail probe (bottom panel) which resided in the tail lobe. The Interball Tail magnetic field data shows a systematic decrease in lobe magnetic field strength that begins at roughly 03:22 UT and ends at about 03:50 UT. The bottom panel shows the energy transfer from the solar wind into the magnetosphere as an epsilon parameter: $\epsilon=\left(4 \pi / \mu_{0}\right) V B^{2} l_{0}^{2} \sin ^{4}(\Theta / 2)$, where $V$ is the solar wind speed, $B$ is the magnitude of the solar wind magnetic field, $l_{0}=7 R_{E}$ is an empirical scaling parameter, and $\tan (\Theta)=B_{Y} / B_{Z}$ defines the IMF clock angle (Akasofu, 1981). Epsilon is calculated from the WIND satellite data and propagated to the magnetopause according to the average solar wind velocity and the upwind position of WIND. Within the uncertainty in timing, which realistically is at least $\pm 5 \mathrm{~min}$, the epsilon parameter starts to decrease simultaneously with the decreasing lobe field recorded by Interball Tail. Geosynchronous observations by GOES 8 (nominal

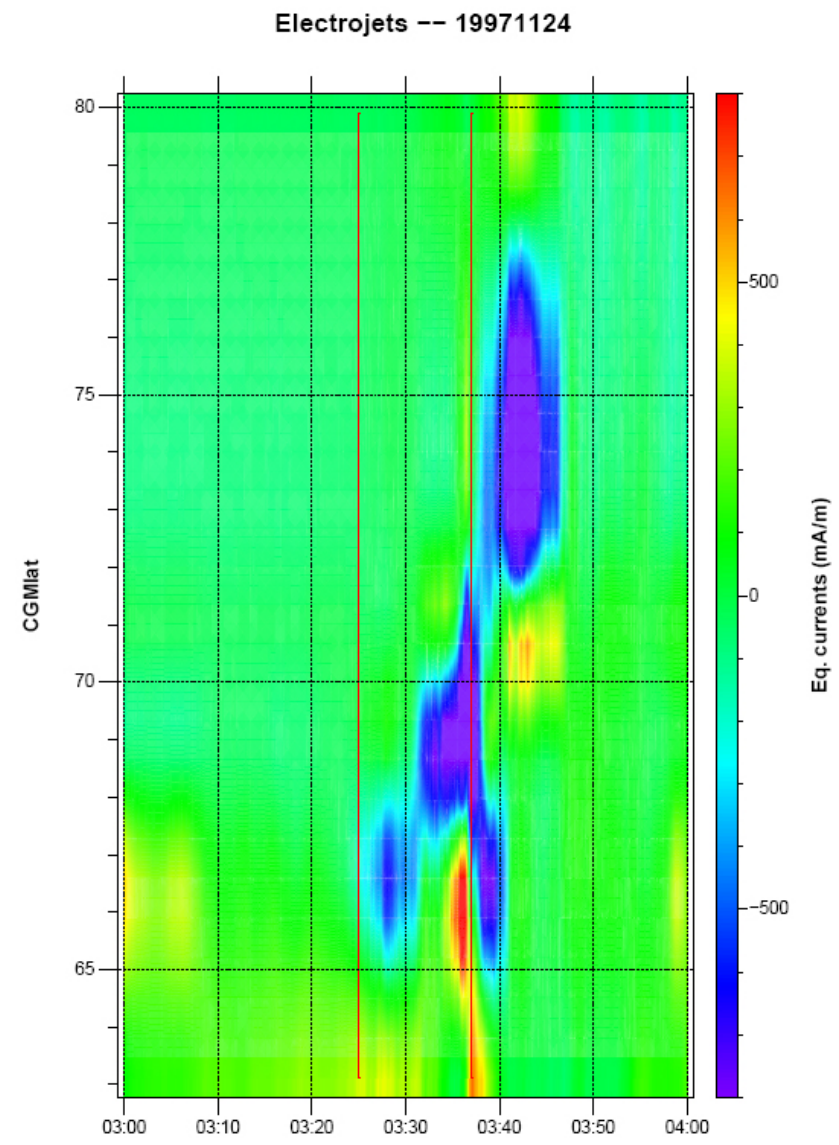

Fig. 5. Electrojet current densities $(\mathrm{mA} / \mathrm{m})$ deduced from the ground magnetic field measurements using the method of upward continuation by Amm et al. (1999). The electrojet is westward when the current is negative (blue), and eastward when the current is positive (red). The vertical lines mark the times of the onset at 03:25 UT and the N-S aurora at 03:37 UT.

footpoint locations are shown in Fig. 2) show a clear dipolarisation beginning roughly at 03:32 UT as indicated by an increase in the tail $B_{Z}$ and decrease in $B_{X}$ (GOES 8 data in Fig. 3). There are small fluctuations in the GOES 8 and 9 inclination around 03:22 UT that coincide with the first dipolarisation type signatures found in the proton auroral emission.

\subsection{Bulge-related signatures in the ionosphere}

In spite of the high level of background activity the substorm signatures were clearly evident in the data. According to the Polar UVI images, the auroral onset took place close to GIL at about 03:25 UT. Figure 4 shows the main optical features of the substorm as captured by the GIL ASI (upper panel) and MSP (lower panel): a northward expansion of the aurora and a sequence of arcs drifting equatorward from the poleward boundary of the bulge (03:27-03:31 UT), a spiral pair (at 03:32 UT) and a N-S aurora (03:37 UT). The initial 


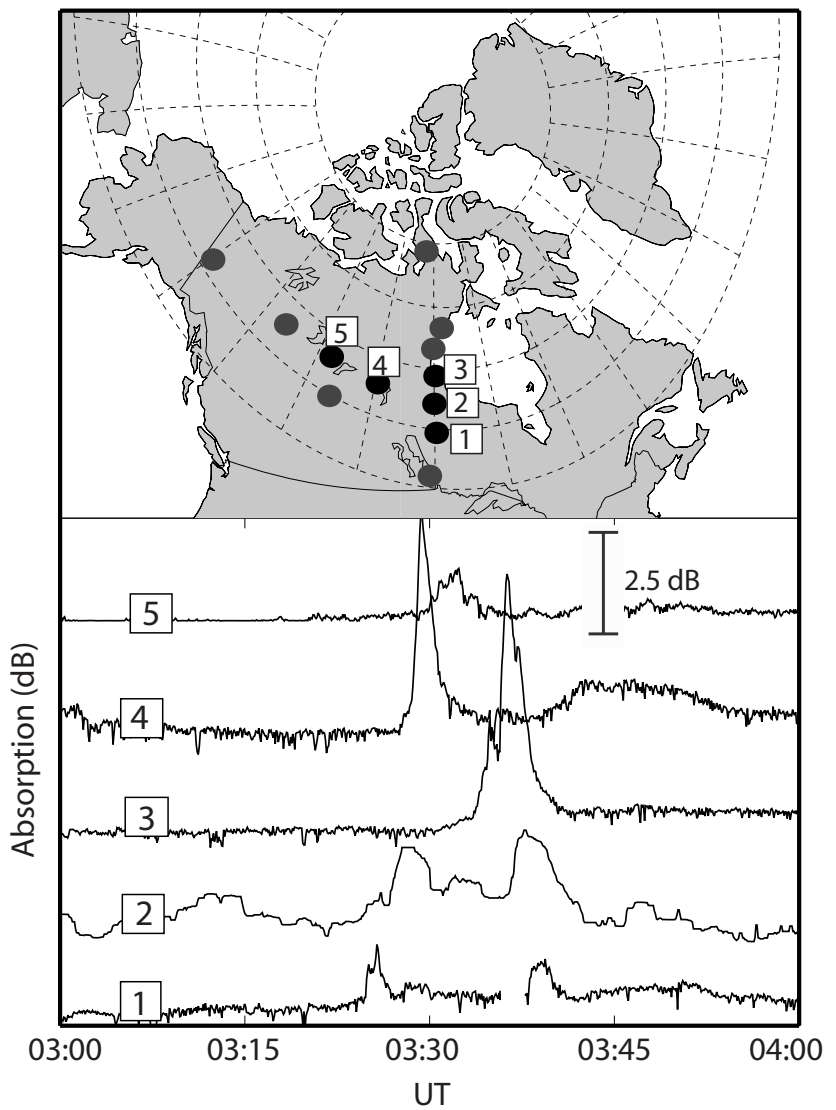

Fig. 6. Riometer recordings from ISL (number 1), GIL (number 2), FCC (number $3,58.76^{\circ} \mathrm{N}$ ), RAB (number $4,58.22^{\circ} \mathrm{N}$ ) and FSM (number $5,60.03^{\circ} \mathrm{N}$ ). First northward and then westward propagation of the absorption event is clearly visible. Gillam data has been filtered and the signal is good for timing purposes.

brightening was observed at about 03:24 UT in the MSP data, which is about one minute earlier than what was suggested by the Polar UVI recordings.

Figure 5 shows the auroral electrojet current density calculated from the ground-based magnetic field recordings using the one-dimensional upward continuation method by Amm and Viljanen (1999). This method utilises spherical elementary current systems in the ionosphere to construct the equivalent currents that correspond to the magnetic deflections measured on the ground along the magnetic meridian of Churchill (Fig. 1). The temporal resolution is five seconds, which is the resolution of the input magnetometer data. The spatial resolution of the output $(\sim 200 \mathrm{~km}$ in the south and increasing northward) reflects the distances between the stations of the Churchill line. The equatorward motion of the westward electrojet (WEJ, negative current densities indicated by the blue colours) can be seen in the end of the growth phase (03:00-03:25 UT). Then an intensification of the WEJ is observed at the onset time (03:25 UT) between magnetic latitudes of $65^{\circ}$ and $67^{\circ}$. This intensification was

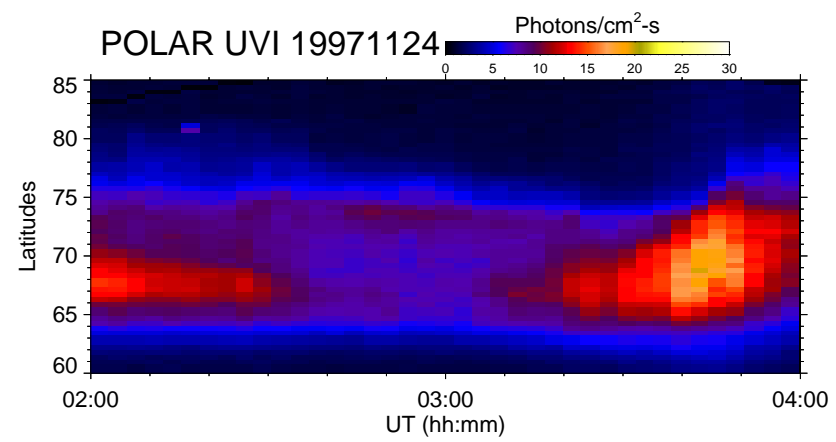

Fig. 7. A Polar UVI keogram along the ESK-FCC-GIL-ISL magnetic meridian. The northernmost blue colours mark the polar cap boundary.

followed by a rapid poleward motion of the westward current channel until the auroral streamer formed and propagated equatorward at 03:37 UT. The streamer was accompanied by a pair of westward and eastward electrojets that underwent a fast equatorward motion together. This kind of behaviour is a typical signature of the streamer-related counter-clockwise vortex of equivalent currents, which has been interpreted as a footprint of intense field-aligned currents within the streamer (Kauristie et al., 2000, 2003). After the streamer intruded equatorward, an intense WEJ was observed even further north (around $75^{\circ}$ ) from the location where the streamer was formed. This corresponds to the poleward expansion of the bulge as seen in the UV keogram (Fig. 7).

A survey of the magnetic X-component variations (data not shown) indicates that the poleward propagating edge of the bulge was latitudinally extended since the negative excursions were recorded also at $\mathrm{RAB}$, roughly 12 degrees to the west from the Churchill line. At the time of the streamer, no such deflection were observed suggesting that the current system of the streamer was azimuthally more localised.

The riometers recorded an absorption spike (see Spanswick et al., 2005) at the same time as the auroral onset (Fig. 6). The first signature was observed at ISL at 03:25 UT followed by a spike-like feature at GIL at 03:26 UT (filtered data) and finally at FCC even further north. This poleward propagation of the rapid increase in the absorption suggests that a front of hard precipitation (energies over $20 \mathrm{keV}$ ) was related to the poleward expanding auroral bulge. In addition to the northward expansion, westward motion of the absorption event was also detected by RAB and FSM, stations located west of the Churchill line. The latter absorption increase seen at GIL and ISL corresponds to the equatorward propagating auroral streamer.

\subsection{Magnetospheric observations}

A Polar UVI keogram along the Churchill line stations (ESK-FCC-GIL-ISL) is shown in Fig. 7. The UV-aurora 


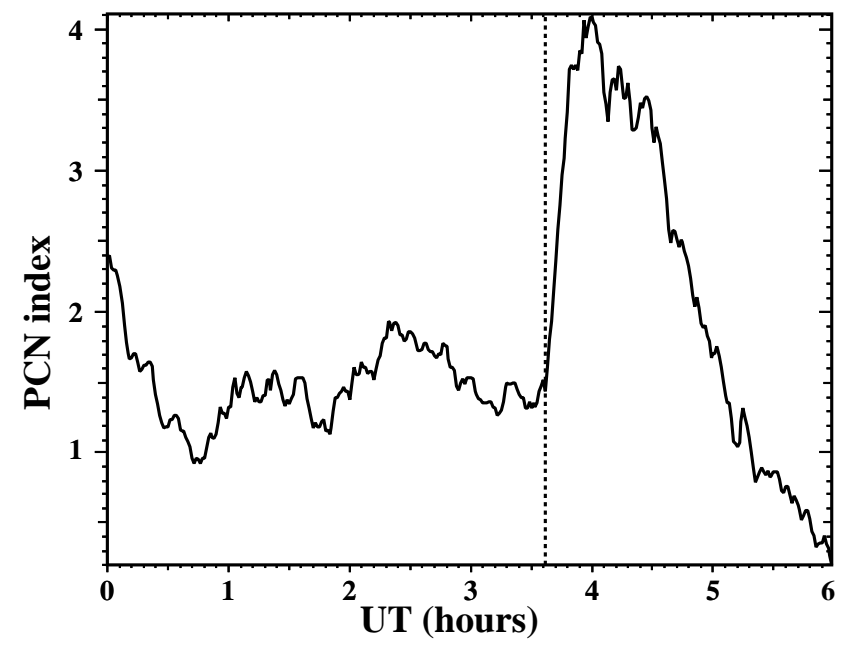

Fig. 8. Variations in the Northern Polar Cap index. Dashed line marks the start of the sudden increase at 03:37 UT.

began to intensify around 03:20 UT and move poleward just before 03:30 UT as an expanding bulge. This behaviour is similar to the MSP data $(557.7 \mathrm{~nm}$ in the lower panel of Fig. 4), although in the UV-regime the contrast between the brightness of the arc at the poleward boundary and the aurora inside the bulge is not as large as in the visible aurora. The poleward expansion is seen to start earlier in the MSP data due to the better spatial resolution. The most important message of the UVI keogram comes from the distribution of the dim aurora (blue colours in the palette): The initial brightening and the first part of the poleward motion of the bulge took place clearly at lower latitudes than the poleward boundary of the dim aurora, which in the evening sector is often associated with the polar cap boundary (separatrix between the closed and the open field lines, see Baker et al., 2000). The UV-bulge reached the poleward boundary only around 03:36-03:37 UT when the dim aurora started to migrate towards higher latitudes. Thus, the auroral activity inside the bulge were caused by processes on closed field lines until about 03:36 UT; only after the bulge had reached the Polar Cap boundary did the reconnection of open field lines take place (Friedrich et al., 2001).

The Northern Polar Cap (PCN) index (Troshichev et al., 1979), shown in Fig. 8, monitors the strength of the polar cap convection with one minute time-resolution. A dramatic increase in the PCN values around 03:37 UT supports this reasoning indicating an enhancement in the convection speed in the polar cap, which is likely to be caused by an intensified nightside reconnection of the open field lines. Simultaneously, there was also a change in the appearance of visible aurora from the southward drifting arcs to the north-south aligned streamers (see Fig. 4).

The variations in the equatorward boundary of the proton aurora have been shown to correlate well with the geostation-

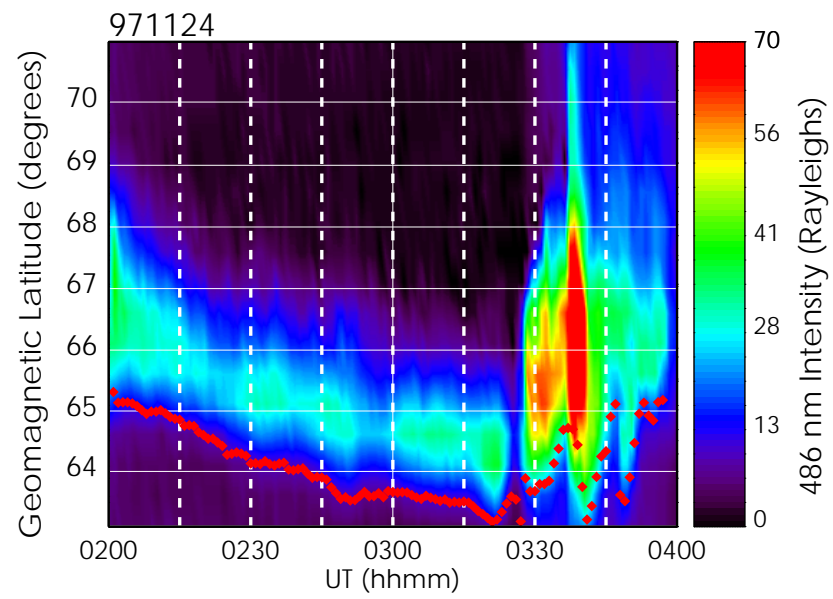

Fig. 9. Proton auroral emission $(486 \mathrm{~nm})$ and the location of its equatorward boundary (red diamonds) (Donovan et al., 2003).

ary inclination changes: when the geostationary magnetic field configuration becomes more dipolar, the proton emission band moves poleward (Donovan et al., 2003). Thus, it is interesting to compare the GOES $B_{X}$ and $B_{Z}$ variations (two upper panels of Fig. 3) with the GIL MSP proton aurora observations (Fig. 9). After the slow equatorward motion during the growth phase (around 02:00-03:20 UT), the MSP data shows a sequence of transient poleward shifts of the $486 \mathrm{~nm}$ equatorward boundary (red diamonds) at 03:22, 03:32, 03:42 and 03:50 UT. At 03:32 UT and 03:50 UT corresponding, nearly simultaneous deviations can be distinguished both in GOES $B_{Z}$ data (excursions to larger values) and in GOES $B_{X}$ data (excursions to smaller values). Surprisingly, the MSP proton data and GOES $B_{X}$ show the first small dipolarisation-like signature at 03:22 UT, i.e. a couple of minutes before the brightening in the electron aurora and the electrojet enhancement. Ten minutes later, a major expansion phase related dipolarisation was recorded by GOES 8 and a simultaneous ASI image from GIL showed a pair of auroral spirals close to the poleward boundary of the proton emission band.

The total magnetic field variations measured by Interball Tail (bottom panel of Fig. 3) describe the magnetic flux changes in the lobe. During the growth phase there should be a flux increase in the tail due to the dayside reconnection, and when the nightside reconnection starts or the current disruption takes place the field should weaken. The variations in the solar wind dynamic pressure also affect the lobe field strength altering the situation governed by the magnetospheric processes alone. During the substorm discussed here, the lobe field measured by Interball Tail increased during 03:00-03:22 UT. At that time, roughly simultaneously with the first dipolarisation signature (03:22 UT as inferred from the MSP data), the lobe field started to decrease. Both the Polar UVI data (Fig. 7) and the PC index (Fig. 8) suggest 
that the reconnection of the open field lines on the nightside started only after 03:36 UT.

\section{Discussion}

This substorm event was characterised by 1) typical growth phase signatures (equatorward motion of the proton band and a decrease of $B_{Z}$ at the geosynchronous orbit) preceding the expansion phase, 2) dipolarisation signatures at the geostationary orbit and a flux decrease in the tail lobe, 3) a bulge with a streamer inside it. However, some of the signatures differ from a typical substorm. For example, no westward travelling surge (WTS) was observed but the auroral bulge was rather void of precipitation. Instead of a WTS, the brightest aurora and the enhanced currents were observed as poleward propagating arc-like structure at the poleward boundary of the bulge.

Spirals were formed inside the bulge but in this case they cannot be interpreted as a sign of instabilities leading to a global reconfiguration of the magnetic field. The growth and decay of this spiral pair occurred within one minute (the interval between two successive ASI images). Compared to the vortices studied by Voronkov et al. (2000) these spirals were approximately of the same size, but clearly faster growing and without a visible stage of saturation - at least in images taken at a cadence of one per minute. This suggests that the spirals were produced by the FAC instability without coupling to the ballooning mode. The spirals formed in an arc much dimmer than the most poleward one.

The N-S aligned auroral streamer showed many of the features described by Sergeev et al. (2001). The poleward boundary of the oval brightened prior to the equatorward intrusion of the streamer and a local brightening both in proton and electron aurora was observed in the equatorward part of the oval when the streamer reached that region. In the nearEarth region, the streamer was related to the dipolarisation similar to the streamer in the case study by Kauristie et al. (2003). The structure appeared about 12 min after the onset, which is also a typical feature according to Deehr and Lummerzheim (2001). Both the southward drifting arcs and the streamer originated from the bright poleward edge of the bulge and thus, they fulfil the characteristics of PBIs (Zesta et al., 2002). According to our observations, the auroral arcs appear as a consequence of the processes within the closed field lines, while the streamer seems to act as a sign of the reconnection of the open field lines. This is an interesting finding, but requires further studies with more events and more comprehensive data. In this context, it is important to carefully locate the polar cap boundary. During the period of the southward drifting arcs (03:27-03:35 UT), we could not use the poleward boundary of $630.0 \mathrm{~nm}$ aurora (data not shown) to identify the open-closed boundary as the signal seemed to be dominated by emissions from altitudes comparable to the $557.7 \mathrm{~nm}$ emissions likely indicating a leakage through the $630 \mathrm{~nm}$ filter of very bright lower-altitude aurora. However, according to the Polar UVI keogram (Fig. 7), the openclosed field line separatrix had much smoother behaviour and clearly resided at higher latitudes.

The Northern Polar Cap (PCN) index strongly increased simultaneously with the streamer observation at 03:37 UT (Fig. 8). The PCN is a proxy for (roughly proportional to) the nightside reconnection rate, so the $\mathrm{PCN}$ recordings suggest that the BBFs are more efficient in carrying the energy earthward from the reconnection site than are the east-west aligned phase fronts (arcs). The increase in PCN also suggests that the processes causing the aurora took place on closed field lines until the streamer occurred at 03:37 UT.

\section{Conclusions}

We have studied and described a substorm event which took place over the CANOPUS network on 24 November 1997. Good coverage of the ground-based data in addition to the Polar UV images provided an overview of the ionospheric electrodynamics. GOES measurements of the tail magnetic field confirmed the dipolarisation. An auroral bulge was formed at the breakup region and an intense breakup arc at its poleward edge moved poleward together with the bulge expansion. A pair of spirals was formed within the faint emissions inside the bulge. About $10 \mathrm{~min}$ after the breakup (5 min after the spiral formation) bright auroral emission was again captured by the ASI in Gillam as the N-S aurora intruded in the FoV. The riometer absorption showed energetic precipitation related to the brightest auroral arc at the poleward boundary of the bulge, and likely also to the equatorward moving streamer. The Polar UVI keogram showed that the streamer was initiated at the time the bulge reached the openclosed field line boundary, just north of the MSP FoV.

The first dipolarisation-like signatures, in the form of a poleward motion of the equatorward boundary of the proton aurora (Fig. 9), were observed a few minutes prior to the brightening of the aurora (at about 03:24 UT) and the first ionospheric signatures of the onset (absorption spike at ISL at 03:25 UT). After the onset, east-west aligned arcs drifted equatorward from the poleward boundary of the bulge, followed by N-S aurora. The major dipolarisation related to the expansion was seen by GOES 8 and 9 satellites at 03:32 UT.

If we interpret our observations according to the $\mathrm{CD}$ scenario, the expansion phase started at 03:25 UT (dipolarisation in the near-Earth region), while in the NENL picture the expansion started at 03:37 UT (reconnection of open field lines). The ground-based observations of the brightening and the poleward expansion of the aurora after 03:25 UT are difficult to interpret as growth phase phenomena as suggested by the NENL model. The ground-based data show first the propagation of the activity from near-Earth to mid-tail (poleward expansion of the auroral bulge) and then in the opposite direction (equatorward intrusion of the streamer), which 
is consistent with the CD model. The polar cap boundary, however, follows the NENL scenario: it shows equatorward drift until 03:37 UT and simultaneously with the start of its poleward expansion the auroral streamer was launched. The arrival of the streamer to the near-Earth region did not trigger any immediate global-scale activity which is the main problem for NENL in this case.

The time delay from the initial dipolarisation type signature $(03: 22 \mathrm{UT})$ to the reconnection of the open field lines (03:36-03:37 UT) was 14-15 min. Consequently, the large energy storage of the lobe magnetic field was not available during the first part of the substorm and thus, this event also demonstrates that processes in the inner magnetosphere can tap enough energy to generate bright aurora and significant fluxes of energetic precipitation.

Interball Tail observations of lobe field decrease starting already at 03:22 UT somewhat complicates the picture. If the field decrease is interpreted as a consequence of the nightside reconnection of the open field lines this did not take place in the CANOPUS MLT sector since the Polar UVI data did not show a poleward motion of the polar cap boundary there. Thus, the near-Earth and mid-tail phenomena would have to occur in different MLT sectors. The decreasing energy input into the magnetosphere $(\epsilon)$ and especially the near-Earth current disruption could also explain the lobe field decrease as the lobe field strength is dictated by the intensity of cross tail current. However, with the available satellite observations in the magnetotail we cannot confirm this connection in this particular case, neither can we estimate the signal propagation time from the near-Earth plasma sheet to the mid-tail lobe. The future Time History of Events and Macroscale Interactions during Substorms (THEMIS) mission with satellites monitoring simultaneously both the mid-tail and nearEarth regions and with the wide-screen television monitor of the ground-based instrumentation will yield us new opportunities to study the magnetospheric processes leading to the substorm onset, and in which circumstances they work.

Acknowledgements. The work of N. Partamies was funded by the Academy of Finland and the Alberta Ingenuity Fund. The Interball Tail, GOES 8 and Wind satellite key parameter data were downloaded from the CDAWeb site and the PCN data from the Danish Meteorological Institute web site. The authors also thank R. L. McPherron for fruitful discussions on the related issue.

Topical Editor M. Pinnock thanks two referees for their help in evaluating this paper.

\section{References}

Akasofu, S.-I.: The development of the auroral substorm, Planet. Space Sci., 12, 273-282, 1964.

Akasofu, S.-I.: Energy coupling between the solar wind and the magnetosphere, Space Sci. Rev., 28, 121-190, 1981.

Amm, O. and Kauristie, K.: Ionospheric signatures of bursty bulk flows, Surveys in Geophysics, 23, 1-32, 2002.
Amm, O., Pajunpää, A., and Brändström, U.: Spatial distribution of conductances and currents associated with a north-south auroral form during a multiple-substorm period, Ann. Geophys., 17, 1385-1396, 1999.

Amm, O. and Viljanen, A.: Ionospheric disturbance magnetic field continuation from the ground to the ionosphere using spherical elementary current systems, Earth Planets Space, 51, 431-440, 1999.

Angelopoulos, V., Baumjohann, W., Kennel, C. F., Coronti, F. V., Kivelson, M. G., Pellat, R., Walker, R. J., Luehr, H., and Paschmann, G.: Bursty bulk flows in the inner central plasma sheet, J. Geophys. Res., 97, 4027-4039, 1992.

Baker, D. N., Pulkkinen, T. I., Angelopoulus, V., Baumjohann, W., and McPherron, R. L.: Neutral line model of substorm: Past results and present view, J. Geophys. Res., 101, 12975-13010, 1996.

Baker, J. B., Clauer, C. R., Ridley, A. J., Papitashvili, V. O., Brittnacher, M. J., and Newell, P. T.: The nightside poleward boundary of the auroral oval as seen by DMSP and the Ultraviolet Imager, J. Geophys. Res., 105, 21 267-21 280, 2000.

Baker, K. B. and Wing, S.: A new magnetic coordinate system for conjugate studies at high latitudes, J. Geophys. Res., 94, 91399143, 1989.

Blanchard, G. T., Lyons, L. R., Samson, J. C., and Rich, F. J.: Locating the polar cap boundary from the observations of 6300 Åauroral emission, J. Geophys. Res., 100, 7855-7862, 1995.

Brittnacher, M., Fillingim, M., Parks, G., Germany, G., and Spann, J.: Polar Cap area and boundary motion during substorms, J. Geophys. Res., 104, 12 251-12 262, 1999.

Deehr, C. and Lummerzheim, D.: Ground-based optical observations of hydrogen emission of the auroral substorm, J. Geophys. Res., 106, 33-44, 2001.

Donovan, E. F., Jackel, B. J., Voronkov, I., Sotirelis, T., Creutzberg, F., and Nicholson, N. A.: Ground-based optical determination of the optical b2i boundary: A basis for an optical MT-index, J. Geophys. Res., 108, doi:10.1029/2001JA009198, 2003.

Elphinstone, R. D., Murphree, J. S., and Cogger, L. L.: What is an auroral substorm?, Rev. Geophys., 34, 169-232, 1996.

Erickson, G. M., Maynard, N. C., Burke, W. J., Wilson, G. R., and Heinemann, M. A.: Electromagnetics of substorm onsets in the near-geosynchronous plasma sheet, J. Geophys. Res., 105, 25 265-25 290, 2000.

Friedrich, E., Samson, J. C., Voronkov, I., and Rostoker, G.: Dynamics of the subtorm expansive phase, J. Geophys. Res., 106, 13 145-13 163, 2001.

Hallinan, T. J.: Auroral spirals, 2. Theory, J. Geophys. Res., 81, 3959-3965, 1976.

Hameiri, E., Laurence, P., and Mond, M.: The ballooning instability in space plasmas, J. Geophys. Res., 96, 1513-1526, 1991.

Henderson, M. G., Reeves, G. D., and Murphee, J. S.: Are northsouth aligned auroral structures an ionospheric manifestation of bursty bulk flows?, Geophys. Res. Lett., 25, 3737-3740, 1998.

Kauristie, K., Sergeev, V. A., Kubyshkina, M., Pulkkinen, T. I., Angelopoulos, V., Phan, T., Lin, R. P., and Slavin, J. A.: Ionospheric current signatures of transient plasma sheet flows, J. Geophys. Res., 105, 10677-10 690, 2000.

Kauristie, K., Sergeev, V. A., Amm, O., Kubyshkina, M. V., Jussila, J., Donova, E., and Liou, K.: Bursty bulk flow intrusion to the inner plasma sheet as inferred from auroral observations, J. 
Geophys. Res., 107, doi:10.1029/2002JA009371, 2003.

Lanchester, B. and Rees, M. H.: Field-aligned current reversals and fine structure in a dayside auroral arc, Planet. Space Sci., 35, 759-768, 1987.

Liou, K., Meng, C.-I., Lui, A. T. Y., Newell, P. T., and Wing, S.: Magnetic dipolarization with substorm expansion onset, J. Geophys. Res., 107, doi:10.1029/2001JA000179, 2002.

Liu, W.: Physics of the explosive growth phase: Ballooning instability revisited, J. Geophys. Res., 102, 4927-4931, 1997.

Lui, A. T. Y.: Current disruption in the Earth's magnetophere: Observation and models, J. Geophys. Res., 101, 13 067-13 088, 1996.

Lui, A. T. Y.: Current controversies in magnetospheric physics, Rev. Geophys., 39, 535-563, 2001.

Lui, A. T. Y., Chang, C. L., Mankofsky, A., Wong, H.-K., and Winske, D.: A cross-field current instability for substorm expansions, J. Geophys. Res., 96, 11 389-11 402, 1991.

Lyons, L. R., Nagai, T., Blanchard, G. T., Samson, J. C., Yamamoto, T., Mukai, T., Nishida, A., and Kokubun, S.: Association between Geotail plasma flows and auroral poleward boundary intensifications observed by CANOPUS photometers, J. Geophys. Res., 104, 4485-4500, 1999.

McPherron, R. L.: Substorm related changes in the geomagnetic tail: The growth phase, Planet. Space Sci., 20, 1521-1539, 1972.

Pontius Jr., D. H. and Wolf, R. A.: Transient flux tubes in the terrestrial magnetospheres, Geophys. Res. Lett., 17, 49-52, 1990.

Pulkkinen, T.: Pseudobreakup or substorm?, in: Proceedings of the Third International Conference on Substorms, 285-293, 1996.

Reeves, G., Fritz, T., Cayton, T., and Belian, R.: Multi-satellite measurements of the substorm injection region, Geophys. Res. Lett., 17, 2015-2018, 1990.

Rostoker, G., Samson, J. C., Creutzberg, F., Hughes, T. J., McDiarmid, D. R., McNamara, A. G., Vallace Jones, A., Wallis, D. D., and Cogger, L. L.: CANOPUS - A ground based instrument array for remote sensing in the high latitude ionosphere during ISTPGGS program, Space Sci. Rev., 71, 743-760, 1995.

Roux, A., Perraut, S., Robert, P., Morane, A., Pedersen, A., Korth, A., Kremser, G., Aparicio, B., Rodgers, D., and Pellinen, R.: Plasma sheet instability related to the westward traveling surge, J. Geophys. Res., 96, 17 697-17 714, 1991.
Sergeev, V. A., Kubyshkina, M., Liou, K., Newell, P., Parks, G., Nakamura, R., and Mukai, T.: Substorm and convection bay compared: Auroral and magnetotail dynamics during convection bay, J. Geophys. Res., 106, 18 843-18 855, 2001.

Shiokawa, K., Baumjohann, W., Haerendel, G., Paschmann, G., Fennell, J. F., Friis-Christensen, E., Lühr, H., Reeves, G. D., Russell, C. T., Sutcliffe, P. R., and Takahashi, K.: High-speed ion flow, substorm current wedge, and multiple Pi 2 pulsations, J. Geophys. Res., 103, 4491-4507, 1998.

Spanswick, E., Donovan, E., Liu, W., Heibert, T., Henderson, M., and Wallis, D.: Temporal and spatial structure of substorm associated spikes in high energy particle precipitation, in: The Inner Magnetosphere: Physics and Modeling, Geophysical Monograph Series, Volume 155, 2005.

Torr, M. R., Torr, D. G., Zukic, M., Johnson, R. B., Ajello, J., Banks, P., Clark, K., Cole, K., Keffer, C., Parks, G., Tsurutani, B., and Spann, J.: A far ultraviolet imager for the international solar-terrestrial physics mission, Space Sci. Rev., 71, 329-383, 1995.

Troshichev, O. A., Kuznetsov, B. M., and Dmitrieva, N. P.: Polar cap magnetic activity as a signature of substorm development, Planet. Space Sci., 27, 217-221, 1979.

Voronkov, I., Donovan, E. F., Jackel, B. J., and Samson, J. C.: Large-scale vortex dynamics in the evening and midnight auroral zone: Observations and simulations, J. Geophys. Res., 105, 18 505-18 518, 2000.

Yumoto, K., Takahashi, K., Saito, T., Menk, F., Fraser, B., Potemra, T., and Zanetti, L.: Some aspects of the relation between Pi 12 magnetic pulsations observed at $\mathrm{L}=1.3-2.1$ on the ground and substorm-associated magnetic field variations in the near-Earth magnetotail observed by AMPTE CCE, J. Geophys. Res., 94, 3611-3618, 1989.

Zesta, E., Loyns, L. R., and Donovan, E.: The auroral signature of earthward flow bursts observed in the magnetotail, Geophys. Res. Lett., 27, 3241-3244, 2000.

Zesta, E., Donovan, E., Lyons, L., Enno, G., Murphree, J. S., and Cogger, L.: Two-dimensional structure of auroral poleward boundary intensifications, J. Geophys. Res., 107, SIA 6-1, doi:10.1029/2001JA000260, 2002. 